\title{
The Analysis of Financial Market Failure
}

\author{
Weijia Zhang \\ School of Government, Beijing Normal University, Beijing 100875, China \\ cocozwj@outlook.com
}

\begin{abstract}
Based on the rapid development of financial globalization, the inefficiency of financial market is becoming more and more influential to economy development. This paper uses financial market theory and the new classical economic theory to analysis the performance and the causes of financial market failure, summarizes that the characteristics of public articles, information asymmetry and the negative externality of financial system are the main causes of financial market failure. And the government should make full use of market mechanism, combining the government regulation and the market discipline to solve the market failure effectively.
\end{abstract}

Keywords: financial market; market failure; financial regulation.

\section{Introduction}

With the rapid development of financial globalization, the position of financial industry in national economy is becoming increasingly important. However, as an imperfect competition market, the financial market could become inefficient because of market forces, incomplete information, externality and public articles. Financial market failure has bad influences on the efficient allocation of financial resources and the stability of economy. In China, especially, the construction of financial market legs behind other countries, so it is vital to build a healthy financial regulation system to deal with financial market failure. In this study, financial market theory and economics theory is applied to analyze the performance and the causes of financial market failure. Then based on the former analysis, advice is provided for financial market regulation.

\section{Financial market and financial regulation}

In financial market, demanders and suppliers transact financial assets by credit instruments. The financial system can shift the fund from surplus departments to short departments, and transform savings to investment effectively [1]. As the transaction center of financial assets, financial market functions as what are listed below: 1) gathering the scattered social funds; 2) allocating financial resource, and the redistributing of wealth and risk; 3) reflecting the economic operation condition of a country or region; 4) regulating the macro-economic operation.

In order to preserve the health operation of those functions analyzed above, an efficient financial regulation system must be well constructed. Financial regulation should make sure the transfer and distribution of financial resources effectively in time and space [2]. The purposes of financial regulation are preventing the systematic risk of financial system, protecting financial consumers, enhancing the operation efficiency of financial system and promoting the realization of other social goals. In other words, financial regulation should make the financial system function well when financial market failure emerges [3]. When the problems caused by inadequate information harm the welfare, or the cost of market failure caused by externalities exceeds that of market failure and extra regulation cost, the financial regulation should be used to solve those problems [4].

\section{The performance of financial market failure}

The financial market failure can make the function of financial system summarized above unable to give full play. The general situation of financial market failure is shown in figure 1 . The performances of the financial market failure can be described as follows: 1) Unreasonable allocation of financial resource: In financial market, the allocation of financial resources is supposed to follow the basic principles of capital and efficiency. However, because of the Matthew Effect, the one which 
has enough resources is in a strong position in the competition, making the allocation of financial resources inefficient. 2) Imperfect competition and monopoly: Financial organization is a special enterprise which uses currency as management object, and the particularity of its services or products makes the free competitive rules not applicable. 3) Imbalance of regional financial development. In the situation of financial market failure, the market mechanism is conducive to the area which has good economic conditions and high starting point. By this means, it will further expand the regional imbalance.

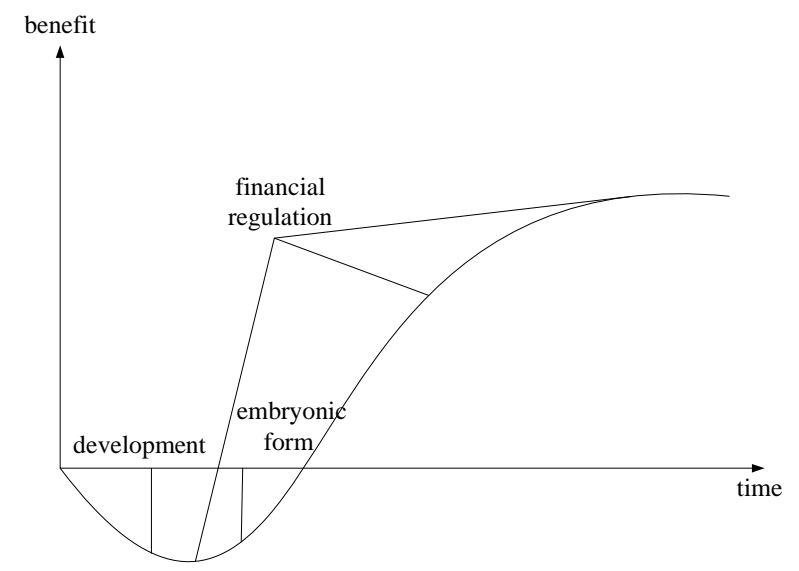

Fig. 1 financial market and financial regulation

\section{The causes of financial market failure}

The main reason of financial crisis is market failure. According to the new classical economic theory, financial market failure is caused by public articles, externality and market monopoly. In order to realize the Pareto-optimality of the allocation of resources, those problems somehow should be eliminated or reduced by financial regulation. In this section, I will analyze the causes of the financial market failure.

\subsection{The characteristics of public articles}

The financial system has the characteristics of public articles. In financial market, the benefit of a fair, stable and efficiency financial system, which is shared by the whole society, is impartible. Even if it increases individual consuming, it also won't affect the cost. In the following part, we analyzed the Pareto-optimality conditions of public articles consumption and the inefficiencies of private supply of public articles.

Suppose that the cost of $\mathrm{q}$ units of public articles is $\mathrm{c}(q)$. Assume $\mathrm{c}(*)$ is twice differentiable, and if $\mathrm{q} \geq 0$ then $c^{\prime \prime}(q)>0$; suppose the quantity of public articles is $x$, and the utility from this public articles perceived by consumer $i$ is $\emptyset_{i}(x)$. Assume $\emptyset_{i}(x)$ is twice differentiable, and if $\mathrm{x} \geq$ 0 then $\emptyset_{i}^{\prime}(x)<0$. Based on this, in a competitive equilibrium which the equilibrium price is $p^{*}$, the equilibrium condition to maximize the quantity of public articles is:

$\max _{q \geq 0} \sum_{i=1}^{I} \emptyset_{i}(q)-c(q)$

The equilibrium condition to maximize the utility of consumer $i$ through the purchase of $x_{i}^{*}$ is:

$$
\max _{x_{i \geq 0}} \emptyset_{i}\left(x_{i}+\sum_{k \neq i} x_{k}^{*}\right)-p^{*} x_{i}
$$

Every consumer's purchase of public articles not only gives himself or herself but also give others benefits, so the private supply brings externalities. If one consumer enjoys the benefit of public articles provided by others without buying enough public articles himself or herself, it will cause the free-rider problem. Suppose we could order consumers by marginal revenue, then only the consumer who could get the biggest marginal revenue will consider providing public articles, while others will not buy the public articles in this equilibrium condition. Suppose that the equilibrium quantity of public articles is $q^{*}$, and it satisfies $\emptyset_{I}^{\prime}\left(q^{*}\right)=c^{\prime}\left(q^{*}\right)$. As we can see, Figure 2 describes the equilibrium condition and Pareto-optimality in this case, and shows that private supply will lead to inadequate consumption of public articles. 


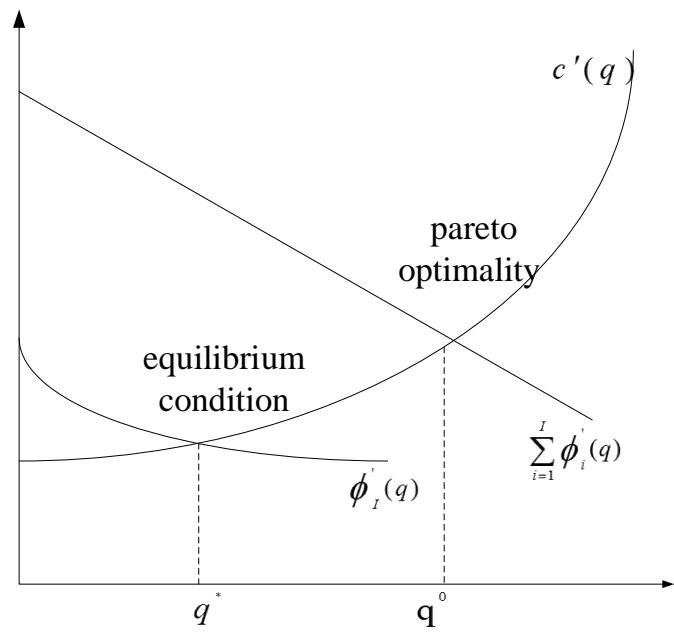

Fig. 2 private supply leads to inadequate consumption of public articles

The non-excludability of financial system can also causes free-rider problem. Because of lacking appropriate incentive mechanism, the consumption of public article is not based on the purchase. In the meantime, the non-competitiveness of financial system determines the private sector cannot provide enough public products, and then causes the market failure. To deal with this problem, the government, public departments and the monetary authorities should use external regulation measures to maintain the stable operation of the financial system.

\subsection{Information asymmetry}

The information asymmetry in financial market can easily cause operating difficulties of operators. However, financial institutions usually cannot afford to the high cost of information collection and processing. Specifically, on one hand, financial institutions cannot accurately determine the borrower's probability of default, which will threaten the safety of banks and lead to credit risks, to some extent affect the interests of depositors. On the other hand, the consumers also cannot obtain the operating conditions and the risk level of financial institutions. Consequently, it is difficult for consumers to distinguish good financial institutions from bad ones, and consumer interests of these institutions could be easily harmed.

Information asymmetry is one of the important reasons for the financial market failure, and it could be reduced by decreasing the chances of financial adverse selection. The financial regulation department should establish a good mechanism of information disclosure to prevent the financial institution providing financial products or services at a low cost unreasonably through the superiority of scale economy.

\subsection{The negative externality of financial system}

The negative externality of financial system is the ripple effect of the foundation of economic growth when financial institutions bankruptcy occurs. The externality is not reflected in market prices, but it is often the source of economic inefficiency. Partial equilibrium is used to analyze the negative externality.

Suppose that the total consumption of the externality of an individual is $\sum_{j} h_{j}(j=1, L, J)$, where the quantity of the enterprises which have externality is $J$. The p denotes the price vector, and when $\mathrm{p}$ is fixed, $\pi_{j}\left(h_{j}\right)$ denotes the indirect profit function. Suppose the total quantity of consumers is I, and their quasi linear utility function is $\emptyset_{i}\left(h_{i}\right)$. In the meantime, suppose that $\pi_{j}(*)$ and $\emptyset_{i}(*)$ are twice differentiable, and $\pi_{j}^{\prime \prime}(*)>0, \emptyset_{i}^{\prime \prime}(*)<0$.

In an unconstrained competitive equilibrium, the Pareto-optimality condition of optimal output of externality $\left(h_{1}^{0}, \ldots \ldots, h_{j}^{0}\right)$ is

$$
\max _{\left(h_{1}^{0}, \ldots \ldots, h_{j}^{0}\right) \geq 0} \sum_{i=1}^{I} \emptyset_{i}\left(\sum_{j} h_{j}\right)+\sum_{j=1}^{J} \pi_{j}\left(h_{j}\right)
$$

For every enterprise $j$, the optimal output of externality $h_{j}^{0}$ has first order condition as follows:

$\sum_{i=1}^{I} \emptyset_{i}^{\prime}\left(\sum_{j} h_{j}^{0}\right) \leq-\pi_{j}^{\prime}\left(h_{j}^{0}\right), h_{j}^{0} \geq 0$ 
$-\pi_{j}^{\prime}\left(h_{j}^{0}\right)$ is the marginal cost of externality of $j$, solving the non-depletion externalities by market, and usually need to make the external market internalized.

The high leverage ratio existing in the financial market makes the interests of the individual financial enterprises and the interests of society serious asymmetry. The externalities caused by bankruptcy of financial enterprise mainly reflects in two aspects: Firstly, the financial enterprise has the characteristics of high and wide range of debt ratios, so a certain bankruptcy of one bank could affect many savers and associated institutions and enterprises, leading to impact on the basis of economy development. Secondly, the bankruptcy of financial enterprise could easily cause systemic financial risk. Due to the vulnerability of the financial system, the collapse of financial institutions is inevitable, but the negative externalities can be solved through appropriate tools--financial regulation is an important way.

\section{Conclusion}

Through the analysis of the financial market failure, this study summarized the causes of market failure. It is mainly caused by the characteristics of public articles, Information asymmetry and the negative externality of financial system. However, the financial supervision and regulation at this stage is inefficiency and could not solve the market failure effectively. Government should make full use of market mechanism, combining the government regulation and the market discipline. Only in this way, can the government makes the financial market stable and improve the regulation efficiency.

\section{References}

[1]Kaufman George G. Bank failure, risk, and bank regulation [J].CATO journal, 1996(16):17-46

[2]Merton R.C. Continuous Time Finance [M], Blackwell, 1990

[3]Stiglitz. J. E. the role of the state in financial market [J]. Proceeding Of the World Bank Annual Conference on Development Economics, 1993(6):19-25

[4]Markus Brunnermeier, Andrew Crockett, Charles Coodhart, Avinash D.Persaud and Hyun Shin. The Fundamental Principles of Financial Regulation [M], Centre for Economic Policy Research, 2009 